\title{
EXTENSIONAL INTERPRETATION OF GENERAL SENTENCES IN SIXTEENTH-CENTURY IBERO-AMERICAN LOGIC*
}

WALTER REDMOND

Universidad Autónoma de Puebla

In this paper we describe some formal similarities between procedures in logic today and in late scholastic propositional analysis. First a notation is sketched out and developed to express quantified categorical statements. Then this language is compared to the extensional interpretation of the general sentence and the quantification methods found in Alonso Gutiérrez de la Vera Cruz (1504-1584, México) and Domingo Soto (1494-1560). We show that this late scholastic analysis is not subject to criticisms brought against earlier forms of such analysis (e.g., in William of Ockham). ${ }^{1}$

\section{Quantified Categorical Logic}

The vocabulary and formation of the language we shall call " $L$ " is as follows. " $f$ ", " $g$ ", . . are (term) variables ranging over entities to which the general expressions " $F$ ", " $G$ ", ... respectively apply. " $f_{1} "$, " $f_{2} ", \ldots$, " $g_{1} "$, " " $g_{2} ", \ldots$ are (individual) constants denoting the entities to which the general expressions " $F$ ", " $G$ " respectively apply. We often choose letters to correspond to meaning. For example " $h_{1}$ " may be read "this human being," "human-one." We call variables and constants "terms." Parentheses "( )" and brac-

- A previous form of this paper was delivered in the Instituto de Investigaciones Filosóficas (UNAM), June, 1980, in response to the topic Logic in colonial Mexico and modern symbolism. In its present form it was read before the Society for Iberian and Latin American Thought at a meeting of the American Philosophical Association, Boston, December 29, 1980.

1 For some background and sortal formalizations of medieval logic see bibliography. 
kets "[]" are universal and particular quantifiers respectively. The slash " $/$ " indicates negation. The wedge " $v$ " and ampersand " $\&$ " are used for (inclusive) disjunction and conjunction.

If $V$ is a variable, $(V)$ and [ $V$ ] are quantified variables and are said to be bound by the quantifier enclosing them. They are read "every $V$ " and "some $V$ " or "at least one $V$. " Constants and quantified variables are called "units." If $U$ and $W$ are units, $U W$ is a sentence and may be read " $U$ is (identical to) $W$." If $U W$ is a sentence, so is $U / W$ and may be read " $U$ is not (identical to) $W$." If $S$ and $T$ are sentences, so are $S \vee T$ and $S \& T$. We presuppose bracketing and other conventions as needed.

The semantics of $L$ must be stated with the help of the $A$ and $D$ operations explained below, but can loosely be described as follows. If a sentence is true, the entity or entities designated by any term must have the associated property, and all the terms must designate the same entity or entities according to the quantification. Thus " $f_{1} g_{2}$ " is true just in case what " $f_{1}$ " denotes has $F$ and what " $g_{2}$ " denotes has $G$, and " $f_{1}$ " and " $g_{2}$ " denote the same thing. " $f_{1}[g]$ " is true just in case " $f_{1}$ " denotes something that has $F$, at least one constant of the form " $g_{n}$ " denotes something that has $G$, and both terms denote the same thing. " $(f)[g]$ " is true just in case every constant of the form " $f_{n}$ " denotes something that has $F$, for every constant " $f_{n}$ " there is at least one constant of the form " $\mathrm{g}_{m}$ " denoting something having $G$, and " $f_{n}$ " and " $g_{m}$ " denote the same thing. The truth conditions of other types of sentences, including negative ones, can be worked out analogously.

The four sentence forms of the standard square of opposition, traditionally referred to as $A$ (e.g., "every human is an animal"), $I$ ("some human is an animal"), $E$ ("no human is an animal", "every human is not any animal"), and $O$ ("some human is not an animal") are symbolized as follows:

$$
\begin{array}{ll}
A: & (h)[a] \\
I: & {[h][a]}
\end{array} \times \begin{aligned}
& E:(h) /(a) \\
& O:[h] /(a) .
\end{aligned}
$$


" $h_{1}[a] "$ ("human-1 is an animal", "... is some animal", "... is at least one animal") is negated by " $h_{1} /(a)$ " ("human-1 is not an animal" in the sense of "not any animal").

We now proceed to tinker with $L$. If we replace parentheses with brackets and vice versa in these expressions, we obtain four general statement forms which are nonstandard in the sense of not belonging to the usual square of opposition. For evample, replacing quantifiers in an $A$ statement gives " $[h](a) . "$ We arrange these forms in a nonstandard square of opposition and refer to them as $F$ (e.g., "every human is every animal"), $R$ ("some human is every animal"), $N$ ("every human is not some animal" in the sense of "not every animal," "for every human, there is at least one animal that he is not"), and $G$ ("some human is not some animal"):

$$
\begin{aligned}
& F:(h)(a) \\
& R:[h](a)
\end{aligned} \times_{G:}^{N:(h) /[a]}\left[\begin{array}{l}
{[a] .} \\
{ }^{2}
\end{array}\right.
$$

" $h_{1}(a)$ " ("human-1 is every animal") is negated by " $h_{1} /[a]$ " ("human-1 is not some animal" in the sense of "not every animal").

A $F$ statement is false except in a world in which only one thing possesses the properties and nothing else possesses them. For example, "every human is every rational being" is true only in a world in which one single being is human and rational and nothing else is. $R$ is false except in a world in which there is only one rational being which is one, but not necessarily every, human being. The case of $N$ and $G$ statements is the opposite of $R$ and $F$, since they are their contradictories.

Now, if we switch the terms in all these sentences, that is, for example, substituting " $a$ " for " $h$ " and " $h$ " for " $a$ ", we

2 The letters " $A$, " "I," " $E$," and " $O$ " are the vowels of "affirmo" and "rnego"; we use " $F$," " $R$," " $N$," and " $G$," the first consonants of these words

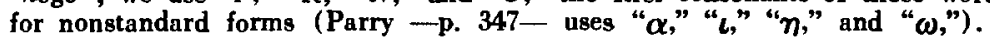


get another set of nonstandard sentences. We will refer to them by placing an asterisk after the letter indicating the unswitched sentence form to which it corresponds. For example, $A^{*}$ corresponds to $A$ and has the form " $(a)[h]$ " and $F^{*}, "(a)(h)$ ", corresponds to $F$. We can likewise arrange these expressions in two more nonstandard squares of opposition: $A^{*}$ ("every animal is a human"), $I^{*}$ ("some animal is a human"), $E^{*}$ ("every animal is not any human"), $O^{*}$ ("some animal is not a human"), $F^{*}$ ("every animal is every human"), $R^{*}$ ("some animal is every human"), $N^{*}$ ("every animal is not some human"), and $G^{*}$ ("some animal is not some human") :

$$
\begin{aligned}
& \begin{array}{l}
A^{*}:(a)[h] \\
I^{*}:[a][h]
\end{array} \times \begin{array}{l}
E^{*}:(a) /[h] \\
O^{*}:[a] /(h)
\end{array} \\
& F^{*}:(a)(h) \times^{*}:(a) /[h] \\
& R^{*}:[a](h) G^{*}:[a] /[h] \text {. }
\end{aligned}
$$

$F^{*}$, like $F$, is true only in a world in which only one thing possesses the properties in question and nothing else possesses them. $R^{*}$ is false except in a world in which, using the previous example, there is only one human being which is one, but not necessarily every, rational being. The case of $N^{*}$ and $G^{*}$ is the opposite of $R^{*}$ and $F^{*}$, since they are their contradictories.

If we allow all the terms to be the same, we obtain still another set of nonstandard sentence forms. We refer to them by placing a prime mark after the letter designating their corresponding multiterm forms. E.g., $A$ ", " $(h)[h]$ " ("every human is a human") corresponds to $A$. $A$ ' and $I$ ' are true in a world containing at least one thing exemplifying the property, and $F^{\prime}$ and $R^{\prime}$ are true in a world containing only one thing exemplifying the property. We can form this square, with statement forms containing constants, according to truth values: 


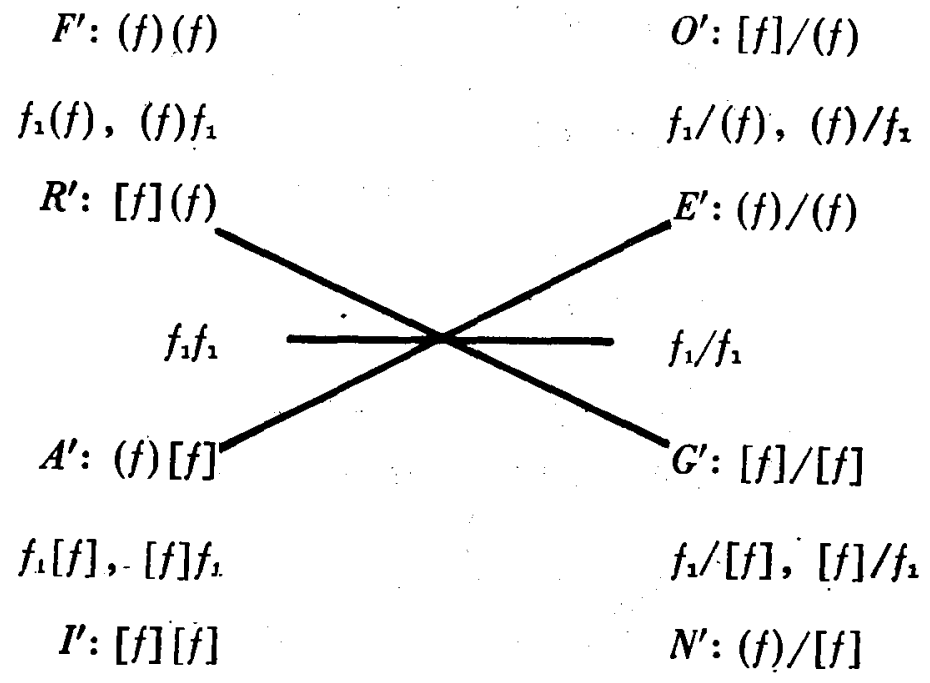

The following schema combines the four squares of opposition of multi-term forms and two additional squares of forms containing constants. The lines between the columns indicate the relation of contradiction between the expressions joined. The arrows point out entailment relations between the various expressions. ${ }^{3}$ Switching units results in an equivalent statement in case the quantifiers are the same or there is at least one constant.

3 Cf. Swiniarski, pp. 216-7. 


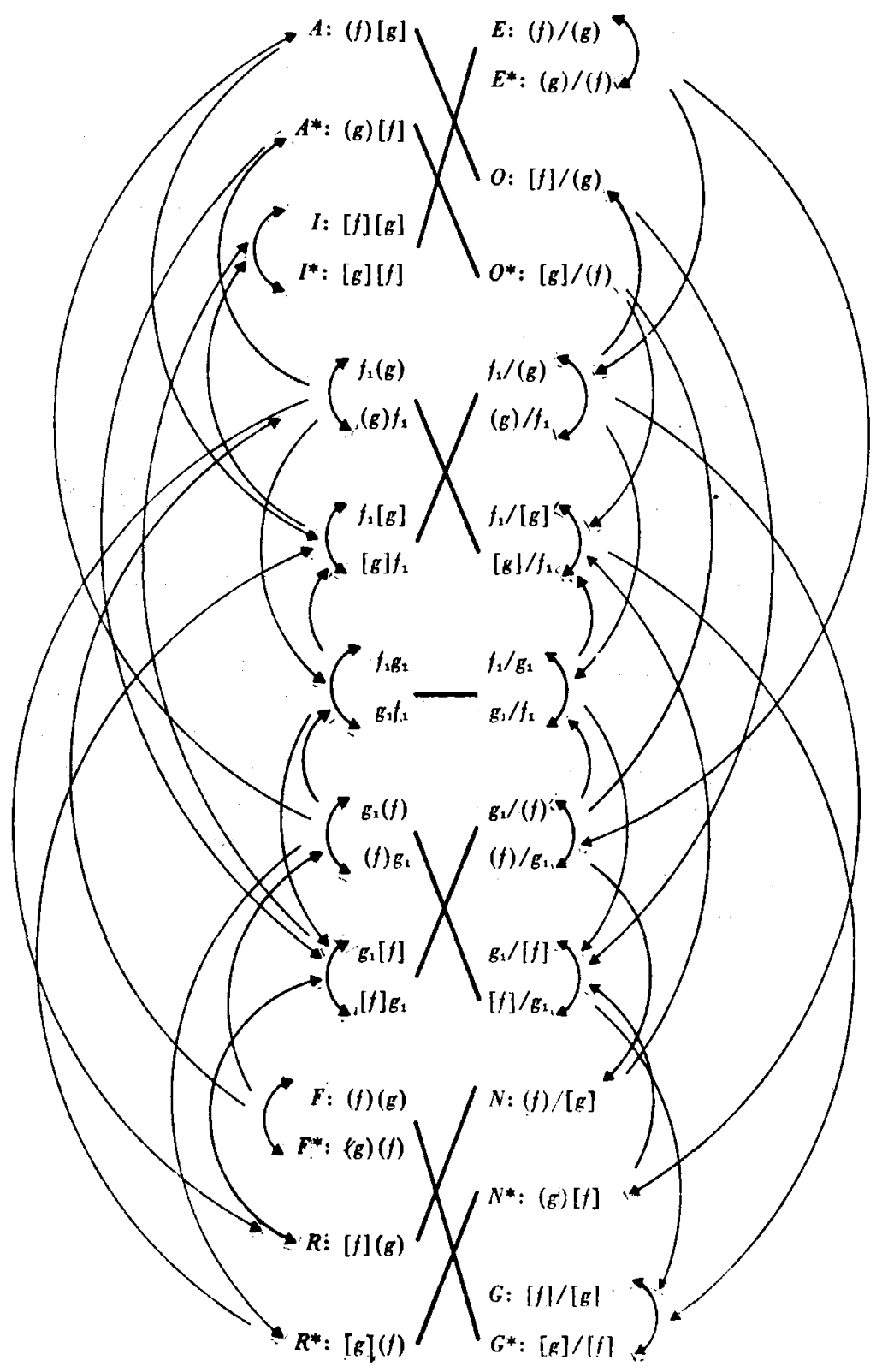

50 
Can we extend the formation rules to allow for sentences with three terms? We would get a large number of possible forms, some of which at any rate, like " $(h)[a][r]$ ". ("every human is an animal and runs") and " $[r](h)[a]$ " ("some runner is every human who is some animal") make some sense (see "leftmost" rule below).

We can now introduce some transformation rules permitting deduction of general sentences to "equivalent" (see qualifications below) sentences containing only constants and conversely. This procedure relates to the discussion in our century about the possibility of analyzing general statements as statements about individuals, e.g., as conjunctions and/or disjunctions of statements about individuals. We call " $D$ "' an operation by which a sentence containing a (bound) variable yields a conjunction or disjunction of sentences in which corresponding serially ordered constants replace the variable. In the case of a conjunction the rule is called " $C D, "$, and if it is a disjunction it is called " $D D$." We call " $A$ " an operation in which a conjunction or disjunction of sentences containing serially ordered constants yields a sentence in which a corresponding (bound) variable replaces the constants. If the first sentence is a conjunction, the rule is called " $C A$." and if it is a disjunction, it is called " $D A$." In these rules, " $\phi U$ " indicates a sentence containing unit $U$; if $U$ is a (bound) variable, no other (bound) variable occurs to the left (that is, $A$ and $D$ operations must apply to the leftmost variable). ${ }^{4} T$ is a term, variable or constant.

$$
\begin{array}{l|lll}
1 & \phi(T) & & \\
2 & \phi T_{1} \& \phi T_{2} \& \ldots \& \phi T_{n} & 1 & C D
\end{array}
$$

- This convention excludes, for example:

$$
\mid \begin{aligned}
& (f)[B] \\
& -(f) g_{1} \vee(f) g_{2} \ldots \\
& {[f] / g_{1} \&[f] / g_{2} \ldots} \\
& {[f] /(a) .}
\end{aligned}
$$




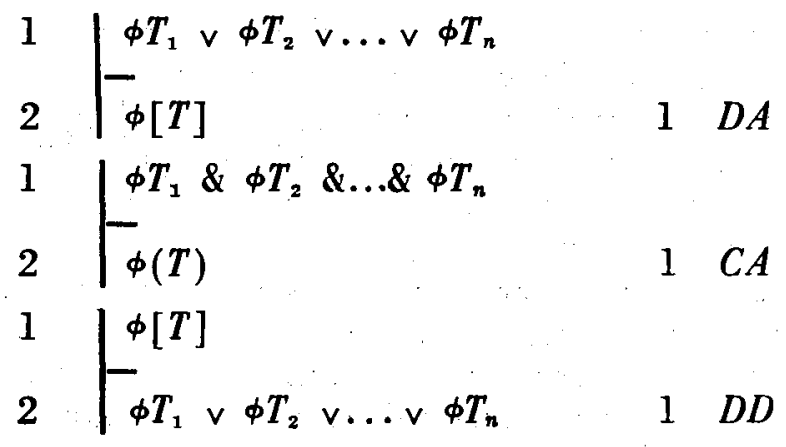

We give two examples of each operation. We may read the first as "if human-l is not any animal, then human-l is not animal-1 and human-1 is not animal-2 and human-l is not animal-n."

\begin{tabular}{l|lll}
1 & $h_{1} /(a)$ & & \\
2 & $h_{1} / a_{1} \& h_{1} / a_{2} \& \ldots \& h_{1} / a_{n}$ & 1 & $C D$ \\
1 & $(h) /(a)$ & & \\
2 & $h_{1} /(a) \& h_{2} /(a) \& \ldots \& h_{n} /(a)$ & 1 & $C D$ \\
1 & $h_{1} a_{1} \vee h_{1} a_{2} \vee \ldots \vee h_{1} a_{n}$ & & \\
2 & $h_{1}[a]$ & 1 & $D A$ \\
1 & $h_{1}[a] \vee h_{2}[a] \vee \ldots \vee h_{n}[a]$ & & \\
2 & {$[h][a]$} & 1 & $D A$ \\
1 & $h_{1} / a_{1} \& h_{1} / a_{2} \& \ldots \& h_{1} / a_{n}$ & & \\
2 & $h_{1} /(a)$ & 1 & $C A$ \\
1 & $h_{1}[a] \& h_{2}[a] \& \ldots \& h_{n}[a]$ & & \\
2 & $(h)[a]$ & 1 & $C A$
\end{tabular}




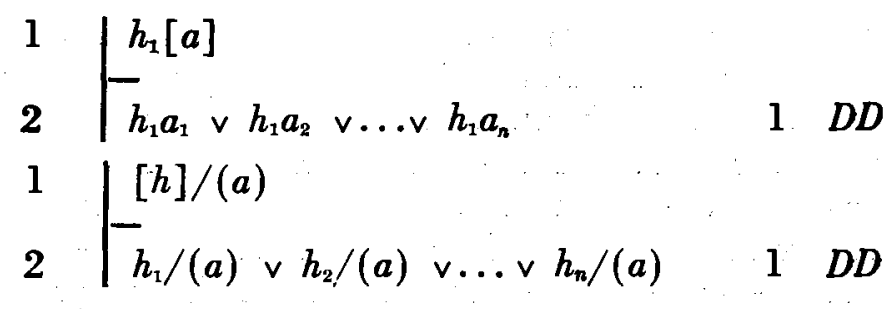

The rules $C D$ and $A D$ could be considered derived in the sense that at least in limited universes of discourse other rules could accomplish the same effect, as can be shown in these derivations of the first examples of $C D$ and $D A$.
\begin{tabular}{r|l}
1 & $h_{1} /(a)$ \\
2 & $h_{1} / a_{1}$ \\
3 & $h_{1} / a_{2}$ \\
$\mathbf{k}$ & $\ddot{h_{1} / a_{n}}$ \\
$\mathbf{k}+1$ & $h_{1} / a_{1} \& h_{1} / a_{2} \& \ldots \& h_{1} / a_{n}$
\end{tabular}
instantiation
instantiation
instantiation
conjunction
introduction

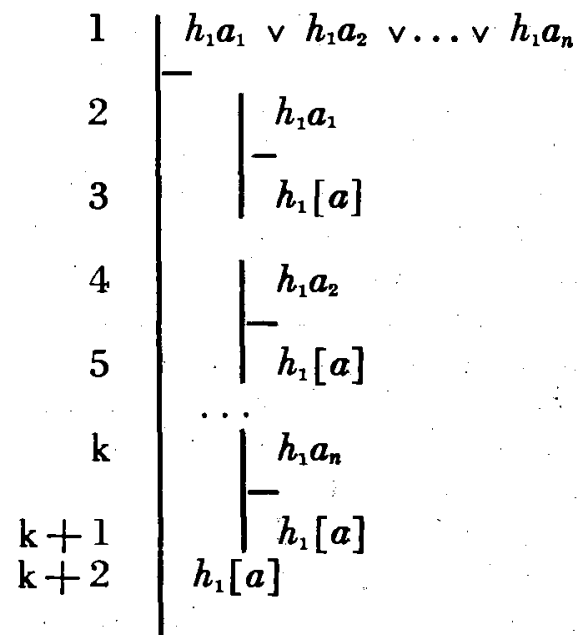
generalization
generalization
generalization
disjunction elimination 
The rules $C A$ and $D D$ are primitive in the sense that even in limited universes customary rules do not accomplish the same effect. There are difficulties with all four rules, of course, when the individuals in question are not denumerable; for example we have the traditional problem of "complete induction" with $C A$. It should be noted that it is not necessary to say that a general sentence means the same as its analysis; the sentence and its analysis (if the above mentioned problems are solved) are rather equivalent in the sense that the truth conditions are the same for them.

Let us present a simple possible world in which to give some examples. The world contains three objects: the human beings Peter and Paul and a donkey, Platero. Paul and Platero run, but not Peter. There are four properties (sets): human, donkey, animal, and running: $H, D, A, R$. The objects have names according to their properties: Peter is $h_{1}$ and $a_{1}$, Paul is $h_{2}, a_{2}$, and $r_{1}$, and Platero is $d_{1}, a_{3}$, and $r_{2}$. We thus have the sets: $H=\left\{h_{1}, h_{2}\right\}, A=\left\{a_{1}, a_{2}, a_{3}\right\}, D=\left\{d_{1}\right\}$, and $R=\left\{r_{1}, r_{2}\right\}$.

"Human-1 (Peter) is an animal" is true iff (if and only if) the disjunction " $h_{1} a_{1} \vee h_{1} a_{2} \vee h_{1} a_{3}$ " holds; that is, " $a_{1}$ ", " $a_{2}$ " or " $a_{3}$ " must be a name of Peter besides " $h_{1}$ ". "Human-1 does not run" holds iff the conjunction " $h_{1} / r_{1} \& h_{1} / r_{2}$ " is true. "Every human is an animal" is true iff the conjunction of disjunctions " $\left[h_{1} a_{1} \vee h_{1} a_{2} \vee h_{1} a_{3}\right] \&\left[h_{2} a_{1} \vee h_{2} a_{2} \vee h_{2} a_{3}\right]$ " is true. The compound sentence is true because there is one true disjunct in each conjunct (" $h_{1} a_{1}$ " and " $h_{2} a_{2}$ "). "Some animal runs" is true iff the disjunction " $a_{1} r_{1} \vee a_{1} r_{2} \vee a_{2} r_{1} \vee a_{2} r_{2} \vee a_{3} r_{1}$ $\vee a_{3} r_{2}$ " holds. It does because at least one disjunct is true (" $a_{2} r_{1}$ " and " $a_{3} r_{2}$ " are true). "Every human is every animal" is false because " $h_{1} a_{1} \& h_{1} a_{2} \& h_{1} a_{3} \& h_{2} a_{1} \& h_{2} a_{2} \& h_{2} a_{3}$ " is false; it is so because only " $h_{1} a_{1}$ " and " $h_{2} a_{2}$ " are true. "Something running is every human" is false because " $\left[r_{1} h_{1} \& r_{1} h_{2}\right]$ $\checkmark\left[r_{2} h_{1} \& r_{2} h_{2}\right]$ " is false (only " $h_{2} r_{1}$ " is true).

However, "some running thing is every donkey" is true, because its analysis " $r_{1} d_{1} \vee r_{2} d_{1}$ " holds. "Every human is every human" is false because the conjunction " $h_{1} h_{1} \& h_{1} h_{2}$ 
$\& h_{2} h_{1} \& h_{2} h_{2}$ " is false (the equivalent " $h_{1} h_{2}$ " and " $h_{2} h_{1}$ " are false). Yet "every donkey is every donkey" is true since " $d_{1} d_{1}$ " is obviously true. "Everything running is not some donkey" in the sense of " $(r) /[d]$ " is false, but "everything running is not some human", " $(r) /[h] "$ is true, for their analyses are " $r_{1} / d_{1} \& r_{2} / d_{2}$ " (the second conjunct is false) and " $\left[r_{1} / h_{1} \vee r_{1} / h_{2}\right] \&\left[r_{2} / h_{1} \vee r_{2} / h_{2}\right]$ " (only " $r_{1} / h_{2}$ " is false) are so.

\section{Alfonso's Appronch to Sentence Theory}

$L$ is closely parallel to a part of Alonso de la Vera Cruz's treatment of categorical statements. ${ }^{5}$ Of the 16 multi-term general sentence forms, he explicitly mentions at least 13 , and pays special attention, for example, to $R^{*}$ and $N^{*}$. He speaks of many forms containing constants and presupposes them all in his extensional analysis of the general sentence. Of the single-term sentence forms he mentions at least two. The four extensional rules we gave are approximately his (we took the letters " $A$ " and " $D$ " from his own words ascensus and descensus, "ascent" and "descent"). Fray Alonso, then, and his

5 Alonso Gutiérrez de la Vera Cruz studied under Domingo Soto and taught at Salamanca and the newly founded University of Mexico, where he wrote, among other books, two volumes on Logic, Recognitio Summularum and Dialectica Resolutio (Mexico, 1553-4, etc.). We refer to the later revised editons of these works, Salamanca 1573 and 1569 respectively (references indicate page and column and "DR" preceeds allusions to the second work). Soto wrote the logical works Summulae (Burgos, 1529, etc.) and In Dialecticam Aristotelis Commentaria (Salamanca, 1543, etc.). We refer to the latter work in the 1574 edition (giving folio, side, and column). Soto stands closer to the early 16th. century development of "modern" logic in Spain, continuing its revival in the University of Paris after the restauration of the nominalists in 1481. Alonso takes part in a reform of logical studies, strong by mid 16th century, under humanistic and thomistic influence, in partial reaction to the "moderns." This philosophy can be seen as part of the Iberian and Ibero-American siglo de oro.

6 Some references with variations in expression: A: 58B, 59A, see $72 \mathrm{~A}$. I: 57B, 59B, 34B, 57B, 71A. E: 57B, 71A, 59A. O: 57B, 36A, 59B, 60A. F: 38A, 36B. G: see 36B. $A^{*}: 36 \mathrm{~B}$. I* : 57B, 71A. E* : 71A. F* : 36B. $R^{*}: 36 \mathrm{~A}$, 36B, 38A, 38B, 60A. $N^{*}: 36 \mathrm{~A}, 60 \mathrm{~A} . \mathrm{G}^{*}: 36 \mathrm{~B}, 59 \mathrm{~A}$. $\mathrm{A}^{\prime}: 38 \mathrm{~B}, 38 \mathrm{~A}$. R': see 38A. $[f] f_{1}: 38 \mathrm{~A}, f_{1}[g]: 37 \mathrm{~A}, 59 \mathrm{~B}, \boldsymbol{g}_{2}(f): 60 \mathrm{~A}$, etc. Alonso would express an $R$ eentence, e.g., as "omnis animal es, b. homo" and an $N$ one as "a. animal non est homo." 
colleagues, since he is not particularly original in his logic, was interested in the same sort of material and used the same sort of methods to deal with it as we might express in a language like $L$. Of course Alonso's language was quite different from our own symbolic language, and we will consider it briefly before explaining his extensional interpretation of general statements and append a note on his realism.

\section{A. Alonso's Language}

Alonso's object language was Latin, in the form of examples, but a Latin containing artificial stipulations and signs. For example, he used the letters " $a$ " and " $b$ " as quantifiers to express some nonstandard sentences; e.g., an example of an $N^{*}$ sentence is "a. homo non est animal" (" $(a) /[h]$ ") and of an $R^{*}$ sentence "omnis homo est .b. animal" ("[a](h)")." His metalanguage, also Latin, contains many carefully formulated rules; we shall see two examples; changes from one general sentence form to another and the extensional transformations.

Alonso calls the subject and predicate "extremes." Constants in $L$ correspond to "vague, singular (discrete) terms" with this definition (26B): "a common noun with a demonstrative pronoun, like 'this man,' "this lion,", distinguished against the "determined singular term" or "proper noun," like "Peter." It is important to understand that he does not use "proper nouns" in his extensional procedures in order to interpret his claims correctly. ${ }^{8}$ Parallel to quantified variables in $L$ are general terms governed by words like "every" and "some" or by signs like " $a$ " and " $b$ " (he does not use variables). He treats quantifications in his study of the "quantity" of the sentence and especially of "supposition" and ascent and descent. We will show that, as in $L$, two basic types of quan.

Tetters began to be used as quantifiers toward the end of the 15th century; other letters were also used (see Ashwort, pp. 601 and 611 n. 7).

\& See Swiniarski's reply (p. 268) to the criticism of Ockham in W. and $M$. Kneale, The Development of Logic (Oxford: 1968). 
tification are enough to express Alonso's extensional theory. Negation for him has to do with the "quality" of the sentence, and he treats it approximately as we do.

Alonso works with the same basic types of sentences as in $L$, but his interests are of course wider. Besides assertorical sentences he studies modal ones, truth-functionally complex as well as categorical, and sentences with conjoint or disjoint extremes not reducible to simple conjunctions or disjunctions, like "Peter and Paul carry a stone" (79B). He analyzes the truth conditions for sentences with relations like belonging ("any horse of some human is an animal," 61B), with four terms ("a donkey of some white human ran," 62A), with special quantification ("all the apostles are twelve," "every animal - species- was in Noah's ark," 35B), etc. He also discusses $(60 \mathrm{~A})$ confusions in understanding forms like " $g_{1}(h):$ "

In his propositional logic (not neatly set apart), Alonso defines conjunction and (inclusive, 81B) disjunction truthfunctionally and, with entailment, considers them basic (16A, $17 \mathrm{~A}, 75 \mathrm{~A})$. His idea of implication is, analogously, "strict": it is a "conditional consequence" defined as a "valid inference" present when "what the antecedent signifies cannot be without what the consequent [signifies] being so" (75A; this modality will affect the meaning of "extensionality"). Syllogistics is subsumed under consequence logic in the sense that the premises of syllogisms form a conjunction constituting the antecedent of a consequence whose consequent is the conclusion $(16 \mathrm{~B}, 18 \mathrm{~A})$. He also gives rules like simplification, addition, detachment, equivalences like those of De Morgan, etc.

The indications on the semantics of $L$ we made at the beginning of this paper correspond to Alonso's rules. He says (36B) that for a sentence to be true, the terms must "suppose" (we will see this in the context of supposition) and they all must suppose for the same thing(s). But he adds riders to this general rule. Obviously the rules of quantification must be 
observed, and if the sentence is modal, involves time distinctions, or collapses several general sentences, verifying the truth conditions is more complicated.

Alonso does not arrange the nonstandard sentences into squares of opposition nor does he comment on all the entailment relations. He does discuss some relations, for example those between contradictory, contrary, and subcontrary sentences. For example, two sentences are contradictory, he says (58B-59A), only if they have the same extremes understood in the same way, they differ in quality, and their quantification is opposite, that is, iff "every universality of one [sentence] must be changed into a particularity in the other, and conversely", stating the claim as a rule. In terms of $L$, this means that contradiction implies that only one sentence may have a slash and any quantifier(s) must be different. This claim is correct and also applies to sentences with constants (Alonso does not make this application).

He explains (59A) why it is a mistake to violate this rule of contradiction. Let us say we wish to form the contradictory of " $(h)[d]$ " ("every human disputes"). " $(h) /(d)$ " (not changing " $(h)$ " to " $[h] ")$ is wrong because these sentences can both be false, contrary to the law of contradiction, which states that they must differ in truth value. Nor can it be " $[d] /$ $[h]$ " (not changing "[ $[d]$ " to " $(d)$ ") because these two sentences can be true at the same time. Alonso uses a $G^{*}$ sentence here (in his language, "omnis homo disputat" and "aliquis homo non est .b. disputans" are outwardly more parallel). In a world of more than one human-disputant, it is true in the case of everybody disputing that for some disputant at least there is some human being which he or she is not. We can now see one reason why Alonso and his contemporaries are interested in nonstandard sentences: we run into them when we try to examine thoroughly formal aspects of categoricals.

Alonso does not discuss the primitiveness of the $A$ and $D$ rules. However, the apply-at-the-left requirement corresponds to Alonso's order rule, which we consider below, as also his 
doctrine of the constantia, which is an attempt to meet the problems of a not completely accessible universe. Also, many of our examples are his. Alonso would probably accept something like $L$.

\section{B. Alonso's Theory of Extensionality}

The medieval lore of supposition and ascent and descent is the historical context in which Alonso treats extensional theory. The doctrine is found in William of Ockham and others in the 14th century, worked out with much sophistication. However, there is some controversy today over exactly what the theory of personal supposition with ascent and descent was intended to be. Is it a theory of quantification and/ or one of the truth conditions of the categorical sentence? One difficulty in interpreting the doctrine in these ways is that there seemed to be lacking the equivalence necessary between a general sentence and its singular analysis to support such an interpretation. Now, the theory by the 16th century has evolved in certain ways from earlier forms. In particular, Alonso and Soto offer a rule governing the order in which ascent and descent operations are carried out. The effect of this rule, it seems, is to achieve an equivalence (at least in denumerable contexts - see below-) allowing us to view the theory as a theory of quantification and truth conditions. It should be stressed, however, that there are other problems connected with extensional theories, then as now.

Supposition, essential elements of which were in play by the middle of the 13th century, was considered a property of terms when they are used in sentences. It is a semantic theory in which the reference of terms is determined by factors such as the syntactical relations in the sentences where they appear. For Alonso, proper (nonmetaphorical) supposition is called material if a term stands for itself in a sentence (" 'man'is a noun"), simple if a term stands for what it signifies secondarily, i.e., the nature apprehended by the understanding ("man is a species"), and personal if it stands for what it 
signifies primarly: things (33AB-34A) ${ }^{9}$ Personal supposition in turn is discrete if the term is singular (vague or determined), and it is common if it is a general term used as general. The general term in common supposition is quantified ("indefinite" uses - without any quantifying expressionusually count as modified by "some"). Constants in $L$ sentences correspond to vague general terms with discrete supposition.

Alonso defines (31B) supposition in general as the feature of a categorematic (i.e., not logical, etc.) term appearing in a sentence by which it is "verifiable of the thing which it signifies." A term is thus verifiable when a statement of the form "this is a _ _ ", where the blank is to be filled by the term in question, holds. For example, "chimera" in "there is a chimera" and "human" in "a human is an animal" lack and have supposition respectively, because "this is a chimera" does not hold and "this is a human" can be truly asserted. This verification rule is parallel to the first semantic indication we gave for $L$. Obviously in a literal sense its applicability is restricted.

Common supposition contains a quantification theory in some ways similar to that of $L$. Alonso defines the types of common supposition, (confused-) distributive, determinate, and (merely) confused, according to the kinds of valid ascent and descent procedures associated with them. In general, he defines (37A) ascent or "induction" (37B) as a "valid formal consequence in which there is argument from sufficiently enumerated singulars, with a constantia, to their universal," and descent is defined in opposite fashion as argument from a universal sentence to its corresponding singulars. A consequence is valid when the antecedent cannot be true without the consequent being so, and it is formal, he says (37B), in the sense that "any [consequence] of the same form [as a valid consequence] is valid." In other words, any general sentence

\footnotetext{
9 There was a difference of opinion about which should be called "primary" and "secondary." We review here only the basic types of supposition.
} 
(of a certain description) cannot be true without its analysis being true, and conversely. We comment on the constantia below.

Alonso defines (35B) distributive supposition as that "for which conjunctive ascent and descent hold," and gives this example of distributive descent (our vertical line indicates a consequence, with a dash separating antecedent from consequent) :

$$
\begin{aligned}
& \text { every human is an animal } \\
& \text { this human is an animal and this [other] human is an } \\
& \text { animal, etc. }
\end{aligned}
$$

Alonso would theoretically "point" (demonstrare), as in the supposition verification procedure: "this human (pointing to Peter) runs and this human (pointing to Paul), etc." The subject of an $A$ sentence has distributive supposition, and also the predicate of an $O$ sentence (this would follow from the conversion rule for contradictories which we reviewed above), both extremes of an $E$ sentence, subjects of $N, N^{*}, A^{\prime}, N^{\prime}$ sentences, etc. Signs of such supposition are "every," "any," "no," etc.

Determinate supposition, says Alonso (34B), is that "for which disjunctive ascent and descent hold" and gives this example of disjunctive ascent:

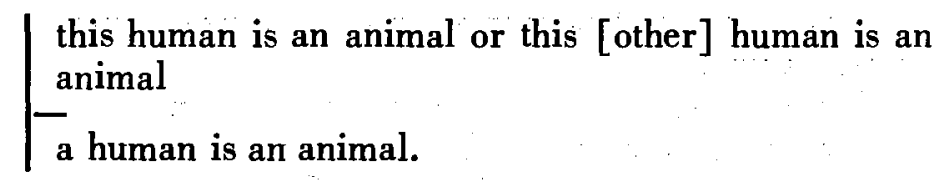

Both extremes of an $I$ sentence, the subject of an $O$ sentence, etc. have determinate supposition, and its signs are "a" (or lack of quantifying term in Latin), "some,", the letter " $b$, ," etc. But we cannot without further ado declare determinate supposition completely parallel to particular quantification in $L$. 
The reason is that confused supposition is also related to particular quantification.

Alonso defines (35B) confused supposition as that "for which disjoint ascent and descent hold." An extreme is "disjoint" if several subject or predicate terms are joined by "or." He gives this example of confused supposition:

$$
\begin{aligned}
& \text { every human is an animal } \\
& \text { this human is this animal or this [other] animal etc. }
\end{aligned}
$$

Here "animal" has confused supposition (this descent is abbreviated). So the predicate of an $A$ sentence has this kind of supposition, and also, says Alonso (35B-36A), the first extreme of " $a$. [ = quantifier] human is not an animal," an $N^{*}$ statement, and it is true in our world since its contradictory, the $R^{*}$ sentence "every human is.$b$. animal," is false. Signs of such supposition are "only" as in sentences like "only humans are wise" (implying "everything wise is human"), the letter " $a$ " and, indirectly, "every," etc. We can say, then, that determinate or confused supposition corresponds to particular quantification in $L$. Actually, Fray Alonso says (82B83B), under certain circumstances sentences with complex extremes (subjects and predicates joined by "or" - disjointor "and") are equivalent to disjunctive and conjunctive sen. tences. It seems that such is indeed the case of the analysis of a sentence with a term that has confused supposition: "this human is this animal or this [other] animal..." is equivalent to "this human is this animal or this [same] human is this [other] animal...."

Why not, then, collapse determinate and confused supposi. tion into a single type and define it simply as that for which disjunctive ascent or descent holds? The reason why we cannot do this without qualification is that invalid inferences would be allowed. Domingo Soto, Alonso's teacher, gives examples of such (44vB-45rA). We cannot argue from "every human is rational" to "every human is this rational thing or every human is this [other] rational thing" since the an- 
tecedent can be true and the consequent false. The consequent here is rather the (partial) analysis of the $R^{*}$ sentence "every human is.$b$. animal." That is, not

$$
\mid \begin{aligned}
& (h)[r] \\
& (h) r_{1} \vee(h) r_{2} \vee \ldots \vee(h) r_{n}
\end{aligned}
$$

but

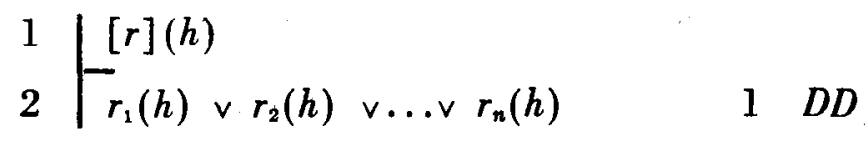

(in the last step the disjuncts are expressed in equivalent form). Again we see a reason why Alonso and his colleagues were interested in nonstandard sentences. In $L$, the invalid inference is blocked by our apply-at-the-left convention.

Nor can we argue, says Soto ( $44 \mathrm{vA})$, from "some human is not this rational thing and some human is not this [other] rational thing" to "some human is not rational," since the antecedent can be true and the consequent false. For example, if there are two human beings, Peter and Paul, and both are rational, it is true to say that some human (Peter) is not this rational thing (Paul) and some human (Paul) is not this other rational thing (Peter). The antecedent is rather a (partial) induction of an $N^{*}$ sentence; that is, not

$$
\mid \begin{aligned}
& {[h] / r_{1} \&[h] / r_{2} \& \ldots \&[h] / r_{n}} \\
& {[h] /(r)}
\end{aligned}
$$

but

$$
\begin{array}{l|l|ll} 
& r_{1}[h] \& r_{2} /[h] \& \ldots \& r_{n} /[h] & & \\
2 & (r) /[h] & 1 & C A
\end{array}
$$

(the conjuncts in step 1 are in equivalent form). $L$ 's apply at-the-left convention blockes the invalid inference.

Now, one way to block such inferences in simply to forbid 
descent from (or ascent to) sentences with confused supposition to (from) a disjunction. Or we can say, as Soto and Vera Cruz do, that we must follow a certain order in carrying out ascent and descent operations. For example, Soto blocks the first invalid inference by the rule: "in regard to a term with confused supposition in the disjoint sense, in relation to a universality, a disjunctive descent is not allowed before that universality is analyzed [resolvatur]" $(44 \mathrm{vB})$. He blocks the second inference $(44 \mathrm{vA})$ by another rule, and adds a third explicitly allowing (except in certain cases) the descent or ascent to begin with either the subject or the predicate "whenever all the terms of a sentence suppose distributively and all suppose determinately," and gives examples of $E$ and $I$ sentences (45rA).

The word "before" in the second last quote seems to imply that we can make a disjunctive descent after analyzing the term with distributive supposition (the "universality"). Soto indeed says $(44 \mathrm{vA})$ :

From this it follows that every mediately or immediately distributive term is in the end to be resolved [tandem resolvendum ] conjunctively, and every non-distributed [term] is in the end to be resolved disjunctively, unless it supposes only-confusedly because of a special sign of the confusion such as are "all" in the collective sense, "I promise," "is required," etc. [as in "all the apostles are twelve," "I promise you a horse," and "to go on horseback a horse is required"]. I say "mediately or immediately" because the order of the resolution demands that we must begin now with one and afterwards with another. For example, although in the sentence "every human is an animal" we may not descend immediately in regard to the predicate, we may after the resolution of the subject has been done.

Alonso does not seem to reduce the ordinary ascent and descent operations to two, but he does insist on an order rule in their application. The first rule is "when there is deter- 
minte supposition in any sentence, the ascent must begin from it, and in the second place from a distributive [supposition], and last from a merely-confused one" (37B). The second rule is "all distributive suppositions among themselves, all confused among themselves, and all determinate among themselves have the same place of probabilitas; for that reason the ascents may begin equally from one as from another term" (38A). The first rule corresponds to cases in $L$ where there are different quantifiers, and the second to cases where one sentence is equivalent to another with reversed units. ${ }^{10}$ Alonso does not need his order rule because he maintains the distinction between disjunctive and disjoint operations, and in fact sometimes ignores it (37B), for example, in:

$$
\begin{aligned}
& \text { every man is this animal or this [other] animal } \\
& \text { every man is an animal. }
\end{aligned}
$$

An example of a descent procedure on "every man is an animal" in $L$, allowing substitution of disjunction for disjoint predicate and presupposing our simplified world:

$$
\begin{aligned}
& 1 \mid(h)[a] \\
& 2 \bar{h}_{1}[a] \& h_{2}[a] \quad 1 \quad C D \\
& 3 \quad h_{1}[a] \quad 2 \text { conj. elim. } \\
& 4 h_{2}[a] \quad 2 \text { conj. elim. } \\
& 5 \quad h_{1} a_{1} \vee h_{1} a_{2} \vee h_{1} a_{3} \quad 2 \quad 2 D
\end{aligned}
$$

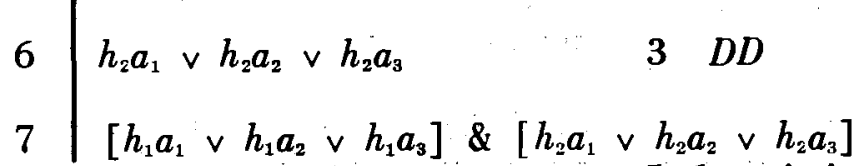

$$
\begin{aligned}
& 5,6 \text { conj. intro. }
\end{aligned}
$$

10 We could make the first rule closer to $L$ by stipulating that the apply. at-the-left convention need be followed only in the case of differing quantifiers. 
An example of an ascent to an $O$ sentence ("some human does not run"):

$$
\begin{aligned}
& 1 \mid\left[h_{1} / r_{1} \& h_{1} / r_{2}\right] \vee\left[h_{2} / r_{1} \& h_{2} / r_{2}\right] \\
& \left.2\right|^{h_{1} / r_{1} \& h_{1} / r_{2}} \\
& 4 \quad \mid \begin{array}{lll}
h_{1} /(r) & 2 & C A \\
h_{1} /(r) \vee h_{2} /(r) & 3 & \text { disj. intro. }
\end{array}
\end{aligned}
$$

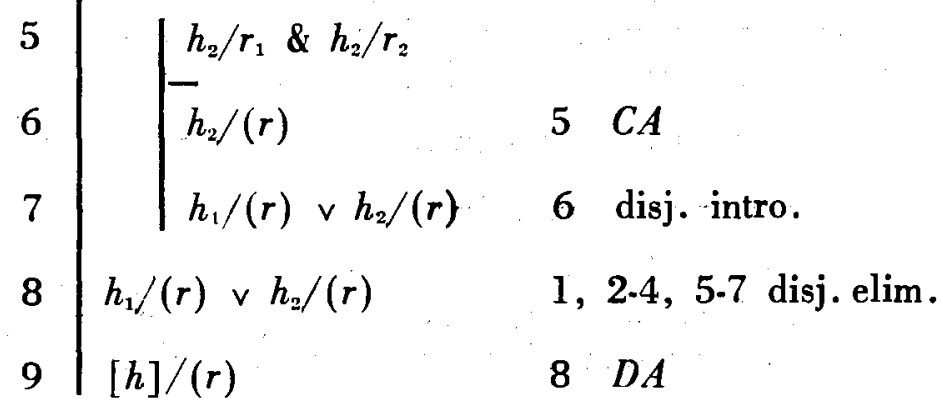

By the way, Alonso interprets the truth value of disjunctive and conjunctive statements as we would (38A):

... if the ascent is carried out under a term which has determinate supposition, it suffices, because it is disjunctive, that one singular [disjunct] be true, since for the truth of the disjunction the truth of one part is enough; but if the ascent is conjunctive, the truth of all the singular [conjuncts] is required, since for the truth of the conjunction, all the parts must be true.

Alonso gives us (37B-38A) an example of a sentence containing three types of supposition in order to show how his order-rule works. His example is an ascent to "every human animal is.$b$. running," where "human" has distributive supposition, "animal" confused (the sense is that every human is 
an animal), and "running thing" has determinate supposition because of the quantifier " $b$." Accordingly, we must first carry out a $D A$ on "animal," then a $C A$ on "human," and finally a $D A$ on "running thing." This translation into $L$ is close to his procedure, which, however, is more laconic and arranged in a slightly different manner (we show only $A$ and $D$ operations) :

$$
\begin{aligned}
& 1 \mid\left[\left[r_{1} h_{1} a_{1} \vee r_{1} h_{1} a_{2} \vee \ldots \vee r_{1} h_{1} a_{n}\right] \&\right. \\
& {\left[r_{1} h_{2} a_{1} \vee r_{1} h_{2} a_{2} \vee \ldots \vee r_{1} h_{2} a_{n}\right] \& \ldots \&} \\
& \left.\left[r_{1} h_{n} a_{1} \vee r_{1} h_{n} a_{2} \vee \ldots \vee r_{1} h_{n} a_{n}\right]\right] \vee \\
& {\left[\left[r_{2} h_{1} a_{1} \vee r_{2} h_{1} a_{2} \vee \ldots \vee r_{2} h_{1} a_{n}\right] \&\right.} \\
& {\left[r_{2} h_{2} a_{1} \vee r_{2} h_{2} a_{2} \vee \ldots \vee r_{2} h_{2} a_{n}\right] \& \ldots \&}
\end{aligned}
$$

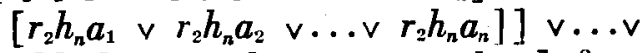

$$
\begin{aligned}
& {\left[\begin{array}{llllll}
r_{n} h_{1} a_{1} & \vee & r_{n} h_{1} a_{2} & \vee & \ldots \vee v & r_{n} h_{1} a_{n}
\end{array}\right] \&} \\
& {\left[r_{n} h_{2} a_{1} \vee r_{n} h_{2} a_{2} \vee \ldots \vee r_{n} h_{2} a_{n}\right] \& \ldots \&} \\
& \left.\left[r_{n} h_{n} a_{1} \vee r_{n} h_{n} a_{2} \vee \ldots \vee r_{n} h_{n} a_{n}\right]\right] \\
& 2 \quad\left[r_{1} h_{1}[a] \& r_{1} h_{2}[a] \& \ldots \& r_{1} h_{n}[a]\right] \vee \\
& {\left[r_{2} h_{1}[a] \& r_{2} h_{2}[a] \& \ldots \& r_{2} h_{n}[a]\right] \vee \ldots v} \\
& {\left[r_{n} h_{1}[a] \& r_{n} h_{2}[a] \& \ldots \& r_{n} h_{n}[a]\right]} \\
& 1 D A \text { (9 times) } \\
& 3 \quad r_{1}(h)[a] \vee r_{2}(h)[a] \vee \ldots \vee r_{n}(h)[a] \\
& 2 C A \text { (3 times) } \\
& 4 \quad[r](h)[a] \\
& 3 \text { (once). }
\end{aligned}
$$

Alonso does not artificially limit the number of objects in universes of discourse, and he should consequently address the problem of representing unmanageable groups. He does treat it (39A) rather cursorily, remarking that in certain types of ascent and descent (he gives examples with $C A, D A$, and $C D$ ) a constantia is needed, which is "a sentence placed in the antecedent [of the $A$ or $D$ consequence] in which mention is made of all the singulars" or contains "virtually all the singulars." 11 Soto and other logicians of his time give a more

11 We have not included the constantia in our examples up to this point. 
extensive treatment, and discuss the import of such phrases as "and thus with the others" and "there are no more," appended to conjunctions or disjunctions of singular sentences. In one example (37A), Alonso uses both a constantia (the second premise) and a qualifying phrase:

this human strives to know, and this [other] human strives to know, and thus with the others these humans are all the humans

every human strives to know.

We can now see in a general way how Alonso viewed the formation of an A sentence like "every human is rational" (37B) :

\begin{tabular}{|c|c|c|}
\hline 1 & $\begin{array}{r}{\left[\begin{array}{lll}h_{1} r_{1} \vee h_{1} r_{2} \vee \ldots \vee & \vee & \left.h_{1} r_{n}\right] \&\left[h_{3} r\right. \\
& \& \ldots \&\left[h_{n} r_{1} \vee\right. & \vee h_{n} r_{2} \vee \ldots . \\
\text { these are all the rational things }\end{array}\right.} \\
\text { the }\end{array}$ & 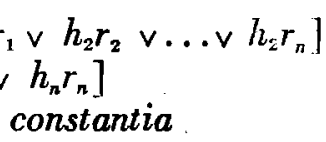 \\
\hline 3 & these are all the humans & constantia \\
\hline 4 & $h_{1} r_{1} \vee h_{1} r_{2} \vee \ldots \vee h_{1} r_{n}$ & 1 simplification \\
\hline 5 & $h_{1}[r]$ & $2,4 \quad D A$ \\
\hline 6 & $h_{2} r_{1} \vee h_{2} r_{2} \vee \ldots \vee h_{2} r_{n}$ & 1 simplification \\
\hline 7 & $h_{2}[r]$ & $2,6 D A$ \\
\hline$k$ & $\ddot{h_{n} r_{1} \vee h_{n} r_{2} \vee \ldots \vee} h_{n} r_{n}$ & 1 simplification \\
\hline$k+1$ & $h_{n}[r]$ & $2, k \quad D A$ \\
\hline$k+2$ & $h_{1}[r] \& h_{2}[r] \& \ldots \& h_{n}[r]$ & $5,7, k \quad 1$ conjun. \\
\hline$k+3$ & $(h)[r]$ & $3, k 2 C A$ \\
\hline
\end{tabular}


It should be noticed that the constantia about rational things is as necessary as the one about the humans in this scheme. It would not be fanciful to see similarities between this theory, showing relations between general sentences and the possibility of reference, and certain approaches to the question of language and reality in our own century.

\section{Alonso's Realism}

In spite of his extensional interpretation of general sentences, Alonso is no nominalist; he actually combines terminist and realist traditions in his logic. He does not follow Peter of Spain in attributing simple supposition to the predicate term in such sentences as "every human is rational." But he does give (34A) the rule that a subject term of first intention (roughly, in object-language) with a predicate term of second intention (roughly, in metalanguage), as in "human is a species," has simple supposition, and he claims (33B) that such a term "supposes for the nature conveyed [importata] in such a term." The word "human" here he sees as discrete, not common, "since it stands for the nature grasped by the understanding as one" (33B). We can even say that "human" with simple and personal supposition "supposes for the same, since in the first case it supposes for a concrete of the human nature which is in the supposita for which 'human' supposes; however with this difference, that in the first [case] it supposes for human as known through its proper concept, that is, 'human,' but in the second it supposes for the same absolutely, that is, not as known in such and such a way."

When Alonso treats the question of universality explicitly in the Dialectica Resolutio, he defends a realist position, arguing for the late scholastic distinction between the formal and objective concepts. The former is a mental act and/or what is formed through it, in any case a reality of an individual person. The formal concept signifies the objective concept, defined as "the thing itself which is understood actually or 
potentially," "the understood intensions which are the things themselves known;" and which "are in continuity with [continuantur] imagined intensions" (DR 16B). The nominalists, he says (DR 17A), reject the objective concept and accept only the formal one.

Thus Alonso's theory of language combines a realism with an extensionalism.

\section{BIBLIOGRAPHY}

E. J. Ashworth, "Multiple Quantification and the Use of Special Quantifiers in Early Sixteenth Century Logic", Notre Dame Journal of Formal Logic, vol. XIX, n. 4, Oct. 1978, 599.613.

G. B. Matthews, "Ockham's Supposition Theory and Modern Logic", The Philosophical Review, vol. 73, n. 1, Jan. 1964, 91-99.

W. T. Parry, "Quantification and Many-Sorted Logic", Philosophy and Phenomenological Research, vol. XXVI, 1965-66.

R. Price, "William of Ockham and Suppositio Personalis", Franciscan Studies, vol. XXX, 1970, 131-40.

G. Priest and Stephen Read, "The Formalization of Ockham's Theory of Supposition", Mind, vol. 86. n. 341, Jan. 1977, 109-31.

T. Smiley, "Syllogism and Quantification", Journal of Symbolic Logic, vol, 27, $1962,58-72$.

J. J. Swiniarski, “A New Presentation of Ockham's Theory of Supposition with an Evaluation of Some Contemporary Criticisms", Franciscan Studies, vol XXX, 1971, 181-217.

H. Weidemann, "William of Ockham on Particular Negative Propositions", Mind, vol. LXXXVIII, n. 350, Apr. 1979, 270-75.

On Fray Alonso de la Vera Cruz see:

W. Redmond, "Formal Logic in New Spain: The Work of Fray Alonso", International Philosophical Quarterly, vol. XIX, n. 3, Sept. 1979, 331-51.

W. Redmond, "La lógica formal en la Nueva España: Aspectos de la obra de Fray Alonso", Latinoamérica (UNAM), vol. 12, 1979, 225-53.

W. Redmond, "Un ejemplo de la cuantificación múltiple en la lógica del siglo XV", Revista de Filosofía (U. Iheroamericana), 1981. 
Alonso de la Vera Cruz (1504-84), quien trabajó durante el llamado siglo de oro de la filosofía escolástica, presentó una interpretación extensional de la oración general (Recognitio Summularum, México, 1554). Si bien los lógicos habían hecho el mismo planteamiento desde la Edad Media, parece que en la escolástica tardía se desarrolló una teoría extensional en el mismo sentido en que se ha propuesto en el siglo $\mathrm{xx}$, y en una formulación que funciona correctamente, al menos en contextos denumerables. Sin embargo, Alonso no es "nominalista", pues integra en su filosofía de la lógica una tesis intensional de las propiedades (Dialectica Resolutio, México, 1554).

Según una teoría extensional, una oración que contiene términos generales es equivalente a un "análisis": otra oración en que los términos individuales reemplazan los términos generales. Describimos brevemente y simplificamos el modo cómo Alonso concibió tal equivalencia, usando para ello un sistema sortal (cuantificación sobre in. dividuos agrupados), formalización en que pueden expresarse comodamente los procedimientos sintácticos del autor.

Aunque Vera Cruz no se restringe de tal manera (trata explícita. mente los problemas de los universos no manejables), suponemos aquí, para simplificar, un dominio con sólo tres individuos. Al primero convienen las dos propiedades $F$ y $G$, y para indicar esto lo nombramos en el sistema " $f_{1}$ " y " $g_{1}$ ". El segundo individuo tiene las mismas propiedades y se nombra " $f_{2}$ " y " $g_{2}$ ". El tercero tiene $G$ pero no $F$, y así se nombra " $g_{3}$ ".

Los nombres " $f_{1}$ " y " $f_{2}$ ", pues, son constantes individuales (Alonso habla de "términos singulares vagos") que denotan los entes a los que se aplica la expresión general " $F$ " (Alonso habla de "términos comunes"), y " $g_{1}$ ", " $g_{2} ", y$ " $g_{3}$ " son constantes que denotan los entes a los que se aplica la expresión general " $G$ ". Introducimos las variables terminales " $f$ " y " $g$ " (Alonso no usa variables explícitamente), las cuales se extienden sobre los entes a los que se aplican las expresiones " $F$ " y " $G$ " respectivamente, los cuantificadores universal " ( )" y particu. lar "[ ]" colocados alrededor de sus variables correspondientes (Alonso usa "todo", "alguno", " $a$ ", " $b$ ", etc.), las conectivas " $v "$, " $\& "$, y "”" para la disyunción, conjunción, y coimplicación, el signo "/" para la negación, y varias reglaś del cálculo funcional (Alonso propone una lógica proposicional aproximadamente como hoy en día).

Describimos informalmente algunos tipos de oraciones categóricas por medio de glosas (Alonso trata éstos y otros tipos): 
$f_{1} f_{1} \quad$ ente-efe-uno es (idéntico a) ente-ge-uno (verdadero en el universo)

$f_{1} g_{2} \quad$ ente-efe-uno es ente-ge-dos (falso)

$f_{1} / g_{2} \quad$ ente-efe-uno no es ente-ge-dos (verdadero)

$f_{1}[g]$ ente-efe-uno es algún ente-ge (verdadero)

(f) $[g]$ todo ente-efe es algún ente-ge, toda efe es ge (verdadero)

$[f][g]$ algún ente-efe es algún ente-ge, alguna efe es ge (verdadero)

$[g](f)$ algín ente-ge es todo ente-efe (falso).

Ahora bien, para reducir una oración general a su análisis, Alonso emplea un procedimiento llamado "descenso" y para formar una oraciốn general a partir de su análisis, emplea el "ascenso" o "inducción". Más aun, define las varias clases de oraciones generales según los tipos de descenso/ascenso que son válidos de ellas. Y porque una oración es verdadera si y sólo si lo es su análisis en el sentido de que las condiciones de su verdad son las mismas, se trata de una interpretación extensional en sentido estricto.

La regla que permite la deducción de un análisis conjuntivo de una oración más general se llama, para Alonso, "descenso conjuntivo" y una que permite la deducción de un análisis disyuntivo de una oración más general se llama "descenso disyuntivo" (también hay reglas para el ascenso). Damos el análisis de una oración universal, “(f) $[\mathrm{g}]$ ", y particular, "[f][g]":

\begin{tabular}{l|ll}
1 & $(f)[g]$ & hipótesis \\
2 & $f_{1}[g] \& f_{2}[g]$ & 1 descenso conjuntivo \\
3 & $f_{1}[g]$ & 2 elim. de la conj. \\
4 & $f_{1} g_{1} \vee f_{1} g_{2} \vee f_{1} g_{3}$ & 3 descenso disyuntivo \\
5 & $f_{2}[g]$ & 1 elim. de la conj. \\
6 & $\begin{array}{l}f_{2} g_{1} \vee f_{2} g_{2} \vee f_{2} g_{3} \\
{\left[f_{1} g_{1} \vee f_{2} g_{2} \vee f_{1} g_{3}\right] \&} \\
{\left[f_{2} g_{1} \vee f_{2} g_{2} \vee f_{2} g_{3}\right]}\end{array}$ & 5 descenso disyuntivo \\
7 & 4,6 intro. de la conj.
\end{tabular}

La oración universal (paso 1) es verdadero si y sólo si su análisis (paso 7) es verdadero, pues si toda efe es ge, entonces " $f_{1} g_{1}$ " $y$ " $f_{2} g_{2}$ " lo son y por ende el paso $1-y$ si " $f_{1} g_{1}$ " y " $f_{2} g_{2}$ " son verdaderos, el paso 1 es verdadero. 


\begin{tabular}{|c|c|c|}
\hline 1 & {$[f][g]$} & hipo. \\
\hline 2 & $f_{1}[g] \vee f_{2}[g]$ & 1 desc. disy. \\
\hline 3 & $f_{1}[g]$ & hipo. \\
\hline 4 & $f_{1} g_{1} \vee f_{1} g_{2} \vee f_{1} g_{3}$ & 3 desc. disy. \\
\hline 5 & $\begin{array}{l}{\left[f_{1} g_{1} \vee f_{1} g_{2} \vee f_{1} g_{3}\right] \vee} \\
{\left[f_{2} g_{1} \vee f_{2} g_{2} \vee f_{2} g_{3}\right]}\end{array}$ & 4 intro. de la disy. \\
\hline 6 & $f_{1}[g]$ & hipo. \\
\hline 7 & $f_{2} g_{1} \vee f_{2} g_{2} \vee f_{2} g_{3}$ & 6 desc. disy. \\
\hline 8 & $\begin{array}{c}{\left[f_{1} g_{1} \vee f_{1} g_{2} \vee f_{1} g_{3}\right] \vee \vee} \\
{\left[f_{2} g_{1} \vee f_{2} g_{2} \vee f_{2} g_{9}\right]}\end{array}$ & 7 intro. de la disy. \\
\hline 9 & 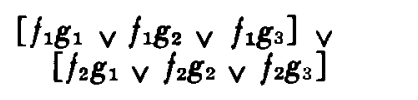 & $2,3-5,6-8$ elim. de la disy. \\
\hline
\end{tabular}

La oración particular (paso 1) es equivalente a su análisis (paso 9), porque es verdadero justamente cuando es verdadero al menos un disyunto del paso $9, \mathrm{y}$ al revés.

Tenemos, pues:

$(f) \equiv\left[\left[f_{1} g_{1} \vee f_{1} g_{2} \vee f_{1} g_{3}\right] \&\left[f_{2} g_{1} \vee f_{2} g_{2} \vee f_{3} g_{3}\right]\right.$

$[f][g] \equiv\left[\left[f_{1} g_{1} \vee f_{1} g_{2} \vee f_{1} g_{3}\right] \vee\left[f_{2} g_{1} \vee f_{2} g_{2} \vee f_{2} g_{3}\right]\right.$. 